\title{
Direct Interactions between the Basolateral Amygdala and Nucleus Accumbens Core Underlie Cocaine-Seeking Behavior by Rats
}

\author{
Patricia Di Ciano and Barry J. Everitt \\ Department of Experimental Psychology, University of Cambridge, Cambridge CB2 3EB, United Kingdom
}

\begin{abstract}
An insidious feature of drug craving and drug seeking in humans is that it can be induced and maintained by conditioned stimuli after a prolonged drug-free period. Understanding the neural basis of this control over addictive behavior may aid in the development of treatments targeting drug seeking and thereby be beneficial in preventing drug use. In the present study, we used a well established animal model to investigate the functional importance of amygdala-nucleus accumbens interactions in cocaine seeking under the control of drug-associated conditioned reinforcers. To probe the direct neuroanatomical relationship between these structures within a functional corticostriatal loop, we used a neuropharmacological disconnection procedure. Thus, infusing a dopamine receptor antagonist unilaterally into the basolateral amygdala (which had no effect on its own) and an AMPA-kainate (KA) receptor antagonist into the contralateral nucleus accumbens core (which also had no effect on its own) greatly reduced cocaine seeking. We also show that bilateral infusions of the DA receptor antagonist into the amygdala, but not nucleus accumbens, or of the AMPA-KA receptor antagonist in the nucleus accumbens, but not the amygdala, also greatly reduced cocaine seeking. The results of this study demonstrate an amygdalanucleus accumbens system that critically underlies stimulus-controlled cocaine seeking and indicate possible neurochemical targets for relapse-prevention medication.
\end{abstract}

Key words: cocaine; nucleus accumbens; basolateral amygdala; second-order schedules; dopamine; kainate; AMPA-KA

\section{Introduction}

Cocaine seeking can be maintained by environmental stimuli that have gained motivational significance through association with the drug (Everitt and Robbins, 2000). Control over drug seeking by the response-contingent presentations of cocaineassociated conditioned stimuli (i.e., conditioned reinforcers) has been modeled in rats using second-order schedules of reinforcement (Arroyo et al., 1998; Schindler et al., 2002) and cue-induced reinstatement paradigms (de Wit and Stewart, 1981; See, 2002; Shaham et al., 2002; Kalivas and McFarland, 2003). Accumulating evidence from these experiments suggests a critical role for dissociable neurochemical mechanisms in the basolateral amygdala (BLA) and nucleus accumbens (NAcc) core that underlie drug seeking maintained by conditioned reinforcers. The special involvement of dopamine (DA) in the BLA in drug seeking is indicated by the observation that infusion of DA, but not glutamate, receptor antagonist into the BLA prevented conditioned stimulus (CS)-induced reinstatement of responding after extinc-

Received April 26, 2004; revised June 28, 2004; accepted June 28, 2004.

This research was supported by Medical Research Council (MRC) Program Grant G9536855 and was conducted within an MRC Center in Behavioral and Clinical Neuroscience. We thank Prof. T. W. Robbins and Dr. R. N. Cardinal for feedback on a previous version of this manuscript. We also thank H. C. Fibiger (Eli Lilly, Indianapolis, IN) for the gift of LY293558.

Correspondence should be addressed to Patricia Di Ciano, Department of Experimental Psychology, University of Cambridge, Downing Street, Cambridge CB2 3EB, UK. E-mail: pd241@cam.ac.uk.

D0I:10.1523/JNEUROSCI.1581-04.2004

Copyright $\odot 2004$ Society for Neuroscience $\quad 0270-6474 / 04 / 247167-07 \$ 15.00 / 0$ tion (See et al., 2001). Consistent with these observations are the findings that NAcc DA efflux was not increased during the response-dependent presentation of conditioned stimuli (CSs) in both a reinstatement procedure (Neisewander et al., 1996; Di Ciano et al., 2001a) and during the cocaine-seeking procedure used here (Ito et al., 2000), whereas glutamate, but not DA, efflux was increased in the NAcc of animals engaged in active cocaine seeking (McFarland et al., 2003).

Together, these findings suggest that drug seeking maintained by drug-associated conditioned reinforcers may depend on dopaminergic mechanisms in the BLA and glutamatergic mechanisms in the NAcc core. This raises the issue of whether, given their neuroanatomical connectedness, these neurochemically selective mechanisms in BLA and NAcc core are components of a neuroanatomical subsystem within limbic cortical-ventral striatopallidal circuitry (Groenewegen et al., 1996). Serial interactions between cortical and ventral striatal structures have been demonstrated previously by using so-called "disconnection" lesions in a variety of functional settings, including Pavlovian-conditioned influences on goal-directed behavior (for review, see Cardinal et al., 2002). The disconnection procedure is based on the premise that unilateral manipulations (lesions or inactivation) of two interconnected structures, but on opposite sides of the brain, should result in impairments of function if they are subserved by serial interactions between them (Parkinson et al., 2000).

In these experiments, we combined in a novel way both neuropharmacological and disconnection approaches to investigate 
further a hypothesized functional interaction between DAdependent associative processes in the BLA and glutamatedependent processes in the NAcc core in cocaine seeking under the control of cocaine-paired stimuli. First, dissociable contributions of dopamine and AMPA-kainate (KA) receptors in the BLA and NAcc core to cocaine seeking, as measured using a second-order schedule of reinforcement, were established by investigating the effect of bilateral infusions into either the BLA or NAcc core of the $D_{1}-D_{2}-D_{3}$ receptor antagonist $\alpha$-flupenthixol or the AMPA-KA receptor antagonist LY293558. Next, the hypothesis that the BLA and NAcc core interact serially within a limbic-cortical ventral striatal circuit to underlie cocaine seeking was tested by functionally disconnecting the BLA and NAcc core by infusing the DA receptor antagonist into the BLA on one side of the brain and simultaneously infusing the AMPA-KA receptor antagonist LY293558 into the contralateral NAcc core. The results reveal the importance of direct amygdala-accumbens interactions in cocaine seeking.

\section{Materials and Methods \\ Animals}

Thirty male Lister hooded rats weighing 280-300 gm at the time of catheter surgery (Charles River, Kent, UK) were individually housed under a reversed $12 \mathrm{hr}$ light/dark cycle (lights on at 8:00 P.M.) and implanted with intravenous catheters as described previously (Di Ciano and Everitt, 2001).

\section{Apparatus}

Rats were tested in operant chambers $(29.5 \times 32.5 \times 23.5 \mathrm{~cm}$; Med Associates, Georgia, VT). Three sides were constructed from Perspex, and the fourth was made of stainless steel, on which two 4-cm-wide retractable levers were secured. The two levers were $12 \mathrm{~cm}$ apart and $8 \mathrm{~cm}$ from the grid floor. Above each lever was a cue light $(2.5 \mathrm{~W}, 24 \mathrm{~V})$, and a red house light $(2.5 \mathrm{~W}, 24 \mathrm{~V})$ was located on the opposite wall. The floor of the chamber was lined with absorbent paper and covered with a metal grid. The testing chamber was placed within a sound- and lightattenuating box equipped with a ventilation fan that also screened external noise. SILASTIC tubing shielded with a metal spring extended from each animal's intravenous catheter to a liquid swivel (Stoelting, Wood Dale, IL) mounted on an arm fixed outside the operant chamber. Tygon tubing extended from the swivel to a Razel infusion pump (Semat Technical, Herts, UK) located adjacent to the external chamber. The operant chamber was controlled by software written in $\mathrm{C}++$ using the Whisker control system (Cardinal, 2000).

\section{Catheter surgery}

Rats were anesthetized with ketamine hydrochloride $(100 \mathrm{mg} / \mathrm{kg}$, i.p.; Ketaset) and xylazine ( $9 \mathrm{mg} / \mathrm{kg}$, i.p.; Rompun) and supplemented with ketamine as needed $(\sim 20 \mathrm{mg})$. All rats were implanted with a single catheter in the right jugular aimed at the left vena cava. Catheters were made in-house from $22 \mathrm{gm}$ cannulas with elongated ends (Brian Fromant, Cambridge, UK). SILASTIC tubing (0.012 inner diameter) was secured to the bottom end of the cannula, and the top was fixed to nylon mesh with dental acrylic and silicone. The mesh end of the catheter was sutured subcutaneously on the dorsum. All surgical instruments were thoroughly sterilized before surgery. To prevent infection, rats were treated postsurgically with $10 \mathrm{mg} / \mathrm{kg}$ Baytril subcutaneously (Genus Express, Burg St. Edmonds, UK) for 8 d (Caine et al., 1992).

\section{Procedure}

Acquisition of cocaine self-administration. Daily experimental testing began 7-10 d after catheter surgery when rats were connected to the intravenous line in the testing box. Active and inactive levers were counterbalanced between left and right sides for individual animals. "Priming" injections of cocaine were never given. During initial training, rats acquired a lever-press response for cocaine $(0.75 \mathrm{mg} / \mathrm{kg}$ per infusion per 0.1 $\mathrm{ml} / 5 \mathrm{sec}$ ) under a fixed ratio (FR) 1 (time-out $20 \mathrm{sec}$ ) schedule of reinforcement. Under this schedule, each bar press resulted in illumination of the stimulus light above the lever, retraction of both levers, and extinction of the house light for $20 \mathrm{sec}$. After this $20 \mathrm{sec}$ interval, the house light was again illuminated, the stimulus light was extinguished, and the two levers were again inserted into the testing box. To prevent accidental overdose, rats were permitted a maximum of 30 infusions per day or a 2 $\mathrm{hr}$ session. Presses on the inactive lever had no programmed consequences but were recorded to assess general levels of activity. After $3 \mathrm{~d}$ of stable responding under this schedule, a second-order schedule was gradually introduced.

Acquisition of responding under a second-order schedule. A secondorder schedule of the type FR $x(\mathrm{FR} y: S)$ was introduced, such that $x$ number of unit schedule requirements resulted in a cocaine infusion as described above, and $y$ number of lever presses resulted in illumination of the stimulus light(s) with extinction of the house light for $1 \mathrm{sec}$ within the unit schedule. Therefore, under a second-order schedule, rats were presented with the following two stimuli: (1) a 1 sec illumination of the stimulus light and extinguishing of the house light after $y$ responses, and (2) a $20 \mathrm{sec}$ illumination of the stimulus light and extinction of the house light during cocaine infusion. The schedule requirements were gradually increased, beginning with a value of $y$ set at 1 and a value of $x$ of 5; each lever press resulted in $1 \mathrm{sec}$ CS presentations, and after five such CS presentations, rats received a cocaine infusion and associated $20 \mathrm{sec}$ presentation of this stimulus light. Subsequently, the response requirements increased to FR10(FR1:S), FR10(FR2:S), FR10(FR4:S), FR10(FR7:S), and FR10(FR10:S). A fixed interval (FI) 15 min (FR10:S) schedule was then introduced, and rats were allowed to stabilize and establish individual patterns of responding under this schedule. Under this schedule, cocaine was available after completion of a FR of 10 responses after an overall FI 15 min had timed out; during the FI 15 min, each FR10 response was reinforced by presentation of the drug-paired CS. Animals were permitted five infusions of cocaine per day under this schedule or a maximum of $2 \mathrm{hr}$.

\section{Stereotaxic surgery}

After training under the second-order schedule of reinforcement, rats were positioned in a stereotaxic frame for insertions of guide cannulas. Each rat was implanted with two sets of bilateral cannulas aimed at the NAcc core and BLA [core: +1.2 anteroposterior (AP); \pm 1.8 mediolateral (ML); -4.7 dorsoventral (DV); BLA: $-2.8 \mathrm{AP} ; \pm 4.5 \mathrm{ML} ;-5.1 \mathrm{DV} ;-3.3$ incisor bar (Paxinos and Watson, 1996)]. Guide cannulas consisted of 24 gauge thin-walled stainless-steel tubing (Cooper's Needleworks, Birmingham, UK) and lowered to $2.5 \mathrm{~mm}$ above the target site. Cannulas were secured with stainless-steel screws and dental acrylic; 29 gauge wire stylets (Cooper's Needleworks) were inserted into the length of the guide cannulas to maintain patency.

\section{Intracerebral microinfusions}

Rats were permitted at least $5 \mathrm{~d}$ to recover from stereotaxic surgery. After re-acquisition of stable responding under a FI15(FR10:S) schedule of reinforcement for $2 \mathrm{~d}( \pm 20 \%$ variation in response rate during the first interval), intracerebral microinfusions were made through a $28 \mathrm{gm}$ injector (Semat Technical, St. Albans, UK), which was lowered to the site of injection, $2.5 \mathrm{~mm}$ below the guide cannula (core, $-7.2 \mathrm{~mm}$; BLA, -7.6 from the skull surface). Infusions consisted of $0.3 \mu$ l delivered over $54 \mathrm{sec}$ simultaneously to both sides of the brain using a syringe pump (model 975A; Harvard Apparatus, Holliston, MA), followed by a $60 \mathrm{sec}$ postinfusion diffusion time. After all infusions, stylets were replaced, and the animal was left in a holding box for $5 \mathrm{~min}$ before testing. All rats received one or two sham infusions of phosphate-buffered water (PB) before testing on separate days to habituate the animal to the injection procedure (PB; composition: $6.4 \mathrm{~mm} \mathrm{Na}_{2} \mathrm{HPO}_{4}, 1.47 \mathrm{~mm} \mathrm{NaH} \mathrm{PO}_{4}, 0.13 \mathrm{M}$ $\mathrm{NaCl}, 2.68 \mathrm{~mm} \mathrm{KCL}$; the $\mathrm{pK}_{\mathrm{a}}$ for this phosphate acid base pair is 6.865 , giving an approximate $\mathrm{pH}$ of 7.5). All infusions were given before test sessions and separated by 1 or $2 \mathrm{~d}$ of stable responding.

Bilateral infusion of LY293558 or $\alpha$-flupenthixol into the NAcc core. Our previous studies demonstrated that responding for cocaine under a second-order schedule of reinforcement was dose-dependently disrupted by infusion of the AMPA-KA receptor antagonist LY293558 bilaterally into the core (Di Ciano and Everitt, 2001) but not after infu- 
sion of the DA receptor antagonist $\alpha$-flupenthixol (our unpublished observations). Thus, to confirm these findings, the lowest effective dose of LY293558 was infused bilaterally into the NAcc core (i.e., at a dose of 0.02 $\mu \mathrm{g})$. LY293558 was a gift from Eli Lilly (Indianapolis, IN) and dissolved in PB. Of the eight rats tested in the disconnection study, six were also infused bilaterally with LY293558. For confirmation of a lack of effect of infusion, $\alpha$-flupenthixol was infused bilaterally at the highest tolerated dose (i.e., $15 \mu \mathrm{g}$ ) (see McFarland and Kalivas, 2001, for use of this strategy).

Bilateral infusion of LY293558 or $\alpha$-flupenthixol into the BLA. The mixed $\mathrm{D}_{1}, \mathrm{D}_{2}$, and $\mathrm{D}_{3}$ dopamine receptor antagonist cis-(Z)-flupenthixol was obtained from Sigma (Poole, UK) and dissolved in distilled water. Pilot studies revealed that infusion of the high dose of $25 \mu \mathrm{g}$ into the BLA produced severe disruption of behavior, and thus four lower counterbalanced doses of $\alpha$-flupenthixol $\left(\mathrm{ddH}_{2} 0,5,10\right.$, and $15 \mu \mathrm{g}$ ) were given according to a Latin-Square design (Keppel, 1991). LY293558 was also infused bilaterally into the BLA at doses that did not produce nonselective effects. The doses used were higher than effective doses in the NAcc core in previous studies (Di Ciano and Everitt, 2001; Di Ciano et al., 2001b) (PB, 0.025, 0.05, $0.1 \mu \mathrm{g})$ and given according to a Latin-Square design (Keppel, 1991).

\section{Disconnection of the BLA and NAcc core}

The lowest effective doses of LY293558 and $\alpha$-flupenthixol were used for the disconnection study. Disconnections were made by infusing animals into the core on one side of the brain and the BLA on the opposite side of the brain. LY293558 was always infused at a dose of $0.02 \mu \mathrm{g}$ (dissolved in $\mathrm{PB}$ ) into the NAcc core, and $\alpha$-flupenthixol was always infused at a dose of $10 \mu \mathrm{g}$ (dissolved in distilled water) into the BLA. The side of infusion was counterbalanced and remained constant throughout the experiment. All rats were given control infusions of the following: (1) vehicle on one side of the NAcc core and vehicle into the BLA on the opposite side, (2) LY293558 on one side of the NAcc core and vehicle into the BLA on the opposite side of the brain, and (3) vehicle in one side of the NAcc core and $\alpha$-flupenthixol into the other side of the BLA. The order of infusions was counterbalanced.

Single, unilateral drug infusions into BLA or NAcc core (with contralateral infusions of vehicle) served as controls rather than double, ipsilateral infusions of drugs into both the BLA and NAcc core (Setlow et al., 2002). This is because the latter, double ipsilateral infusions were predicted based on our previous work (Christakou et al., 2004) to have behavioral effects through major disruption of BLA-NAcc core connections on one side of the brain. The behavioral changes that follow this intra-hemispheric disconnection impair affective stimulus-response processing mechanisms in the animal's environment that are contralateral to the drug-infused hemisphere.

\section{Histological assessment of cannulas placements}

At the end of testing, rats were anesthetized with an overdose of sodium pentobarbitone ( $1.5 \mathrm{ml}$ per animal, i.p., Euthatal; Rhône-Mérieux, Hertfordshire, UK) and perfused transcardially with isotonic saline, followed by $4 \%$ paraformaldehyde with $0.2 \%$ saturated picric acid in $0.2 \mathrm{~m}$ phosphate buffer. Brains were then removed and postfixed before being transferred to a $20 \%$ sucrose solution in 0.01 M PBS for $\sim 24 \mathrm{hr}$ before being sectioned at $60 \mu \mathrm{m}$ using a freezing microtome. Every third section was mounted, stained with cresyl violet, and placements verified under a light microscope.

\section{Statistical analyses}

For all sessions, the number of lever presses on the active and inactive levers were recorded and presented as mean \pm SEM. Data were analyzed with repeated-measures dose $X$ interval ANOVAs to determine whether self-administered cocaine potentiated responding. Two-way ANOVAs were then followed by planned comparisons for each interval. Data were analyzed separately for each lever. For clarity, only the first two intervals (i.e., the drug-free interval and the first interval after cocaine selfadministration) were analyzed. Criteria for significance was set at $p \leq 0.05$.

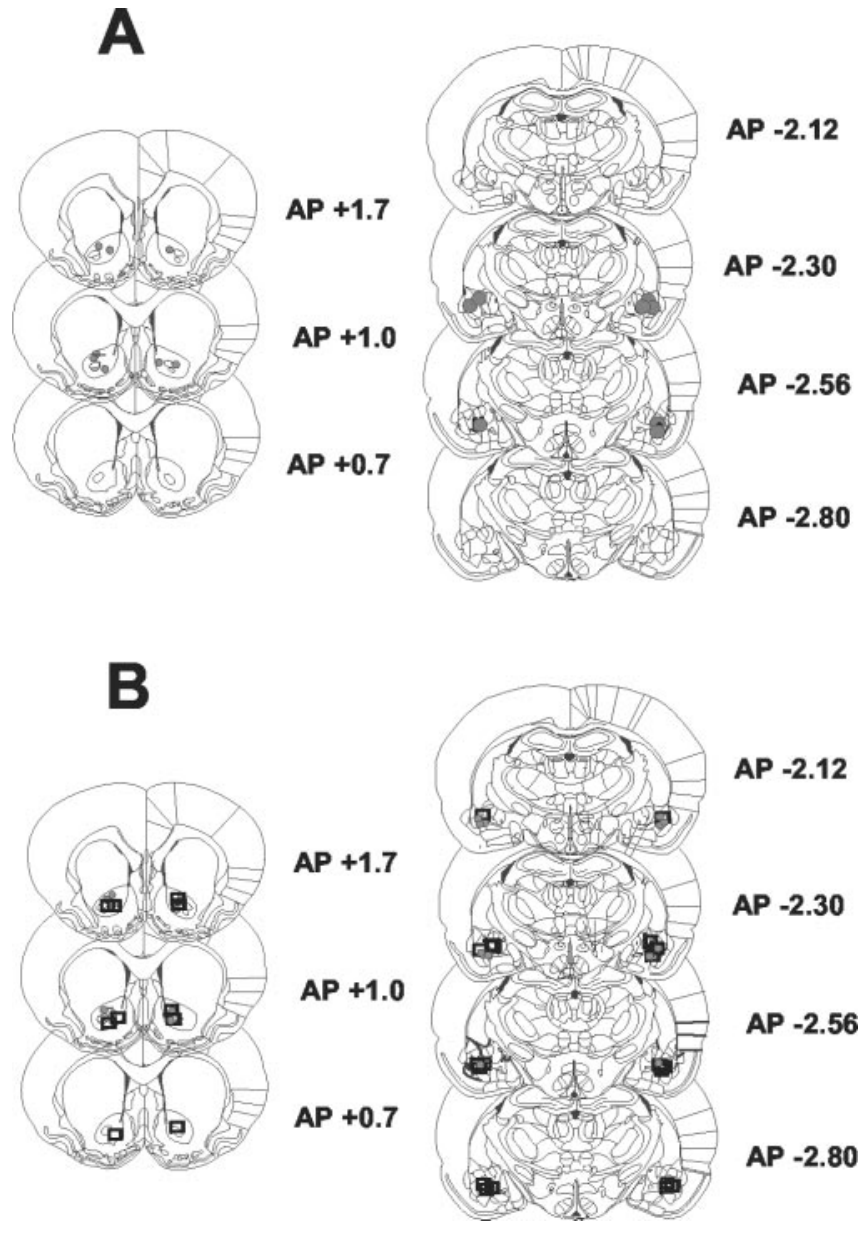

Figure 1. A, Location of the tips of injection cannulas within the NAcc core (left panel) and BLA (right panel) for the disconnection study $(n=8) . B$, Location of the tips of injection cannulas within the NAcc core (left panel) and BLA (right panel) for the study of the effects of bilateral infusion of either LY293558 or $\alpha$-flupenthixol. The locations of tips of cannulas for the $\alpha$-flupenthixol studies are indicated by squares (BLA, $n=11$; NAcc core, $n=5$ ) and marked by circles for the LY293558 study (BLA, $n=6$; NAcc core, $n=6$ ). Schematics of coronal sections are taken from the study by Paxinos and Watson (1996).

\section{Results}

\section{Cannula placements}

Cannula placements are shown in Figure 1. The top panels illustrate the location of the tips of injection cannulas within the NAcc core (left panel) and the BLA (right panel) that were included in the analyses of the disconnection study. The bottom panels show the location of tips of cannulas for bilateral infusion of $\alpha$-flupenthixol or LY293558 in the NAcc (left panel) or BLA (right panel). The coronal sections of the rat brain were taken from Paxinos and Watson (1996).

\section{Effect of disconnection of the BLA and NAcc core on CS- maintained cocaine seeking}

Disconnection of the BLA and NAcc core by infusion of the effective doses of $10 \mu \mathrm{g}$ of $\alpha$-flupenthixol into the BLA on one side of the brain and $0.02 \mu \mathrm{g}$ of LY293558 into the contralateral NAcc core markedly decreased cocaine seeking (Fig. 2) $(n=8)$. Planned comparisons of each treatment to vehicle for each interval revealed a significant effect in the first interval only, and the only treatment that reduced responding was the combined infusion of the DA receptor antagonist unilaterally into the BLA with simultaneous infusion of the AMPA-KA receptor antagonist 


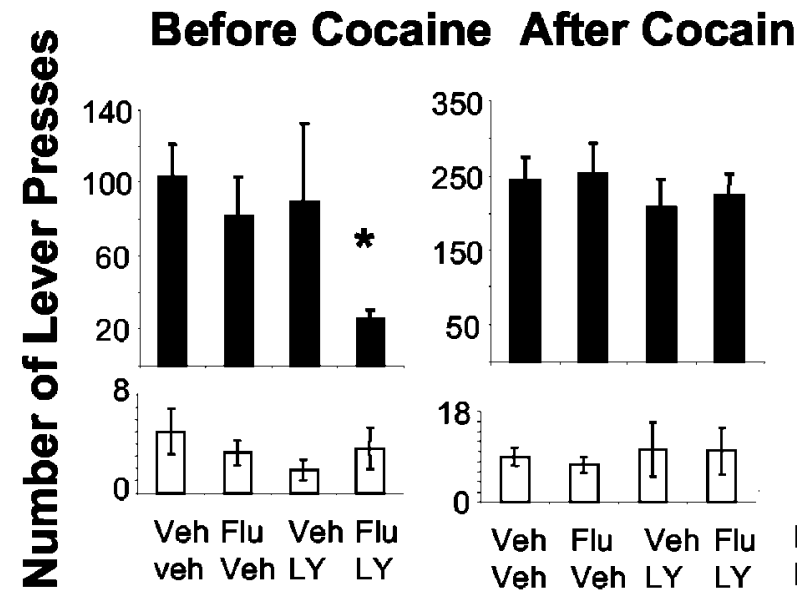

Treatment

Figure 2. $A, B$, Effect of disconnection of the BLA and NAcc core with infusion of $10 \mu \mathrm{g}$ of $\alpha$-flupenthixol (Flu) and $0.02 \mu \mathrm{g}$ of LY293558 (LY), respectively, into these brain loci on the mean \pm SEM number of responses on the active lever (dark bars) and inactive lever (open bars) for cocaine under a second-order schedule of cocaine reinforcement during the first, drug-free interval (left) or after cocaine self-administration (right). The asterisk denotes difference from vehicle (Veh) during that interval $(n=8)$.

LY293558 into the contralateral NAcc core. Unilateral infusion of the DA receptor antagonist into the BLA or unilateral infusion of the AMPA-KA receptor antagonist into the NAcc core had no effect, emphasizing that it was the disconnection of these two structures that significantly impaired cocaine seeking. A two-way dose $X$ interval ANOVA revealed a significant effect of interval $\left(F_{(1,7)}=28.41 ; p=0.001\right)$, confirming that cocaine also increased responding during the second interval. Analysis of responding on the inactive lever revealed no dose effects.

Effect of bilateral infusion of $\alpha$-flupenthixol or LY293558 into the BLA on CS-maintained cocaine seeking

Infusion of four counterbalanced doses of $\alpha$-flupenthixol into the BLA dose-dependently reduced responding for cocaine under the second-order schedule of reinforcement $(n=11)$ (Fig. 3, top panels). A repeated-measures dose $\times$ interval ANOVA revealed significant effects of dose $\left(F_{(3,30)}=4.123 ; p=0.015\right)$ and interval $\left(F_{(1,10)}=32.422 ; p<0.001\right)$, indicating that responding increased by self-administered cocaine in the second interval and decreased during both intervals in rats that received infusions of $\alpha$-flupenthixol into the BLA. Planned comparisons revealed that responding decreased in the first and second intervals (i.e., before and after cocaine self-administration) after infusion of 15 and 10 $\mu \mathrm{g}$ of $\alpha$-flupenthixol, respectively. No significant effects were revealed for responding on the inactive lever.

In contrast, no effect on cocaine seeking was seen after infusion of four counterbalanced doses of LY293558 into the BLA (Fig. 3, bottom panels) $(n=6)$. ANOVA revealed a significant effect of interval only $\left(F_{(1,5)}=39.94 ; p<0.001\right)$, confirming that self-administered cocaine increased responses, but infusion of LY293558 had no effect. Presses on the inactive lever increased during the first interval, an effect that was confirmed by a significant dose effect $\left(F_{(3,15)}=3.76 ; p=0.034\right)$.

Effect of bilateral infusion of $\alpha$-flupenthixol or LY293558 into the NAcc core on CS-maintained cocaine seeking

Infusion of $\alpha$-flupenthixol bilaterally into the NAcc core had no effect on responding for cocaine under a second-order schedule

\section{Before Cocaine After Cocaine}
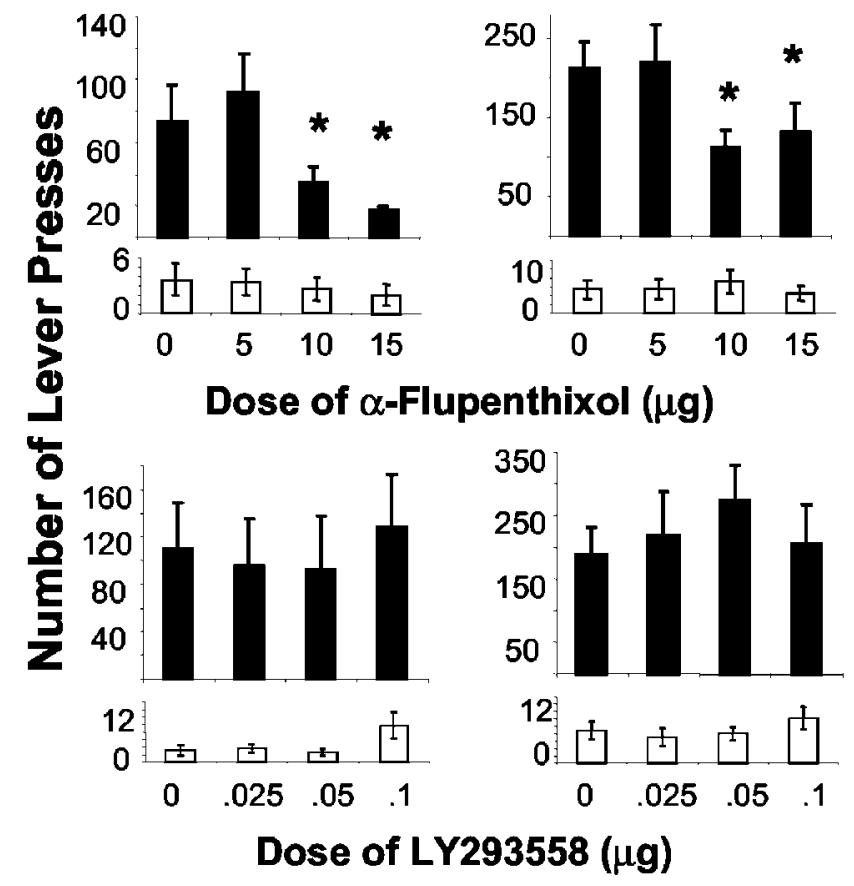

Figure 3. Effect of infusion of four counterbalanced doses of the $D_{1}-D_{2}$ dopamine receptor antagonist $\alpha$-flupenthixol (top panel; $n=11$ ) or the AMPA-KA antagonist LY293558 (bottom panel; $n=6$ ) into the BLA on the mean \pm SEM number of responses on the active lever (dark bars) and inactive lever (open bars) under a second-order schedule of cocaine reinforcement. Responses before self-administered cocaine during the first interval and after self-administered cocaine are given on the left and right panels, respectively. The asterisk denotes difference from vehicle during that interval $(n=11)$.

of reinforcement for cocaine (Fig. 4, top panel) $(n=5)$, confirming our previous findings (our unpublished observations). ANOVA failed to reveal any significant effects. Lever presses on the inactive lever decreased after infusion of $\alpha$-flupenthixol into the NAcc core, an effect that approached significance $\left(F_{(1,4)}=\right.$ 5.29; $p=0.08$ ).

In contrast, bilateral infusion of the AMPA-KA receptor antagonist LY293558 into the NAcc core decreased cocaine seeking (Fig. 4, bottom panel) ( $n=6$, also used in disconnection study), confirming our previous findings with the optimal dose of LY293558 (Di Ciano and Everitt, 2001). Significant effects of dose $\left(F_{(1,5)}=30.62 ; p=0.003\right)$ and interval $\left(F_{(1,5)}=6.15 ; p=0.05\right)$ were revealed, confirming that $0.02 \mu \mathrm{g}$ of LY293558 decreased drug seeking and that self-administered cocaine increased drug seeking in the second interval. Planned comparisons revealed that responding decreased by the AMPA-KA during first interval only (Fig. 4, bottom panel) ( $p=0.05)$, again consistent with our previous findings (Di Ciano and Everitt, 2001). No significant effects were revealed for responding on the inactive lever.

\section{Discussion}

These experiments showed that neuropharmacological disconnection of the BLA and NAcc core greatly reduced cocaine-seeking behavior, thereby revealing the importance of direct interactions between these structures in the control over this behavior by drugassociated conditioned reinforcers. Conditioned stimuli that are delivered response dependently (i.e., conditioned reinforcers) are critical for the maintenance of prolonged chains of behavior (Kelleher, 1966; Goldberg et al., 1975; Everitt and Robbins, 2000), because they allow humans and animals to tolerate delays to 


\section{Before Cocaine After Cocaine}

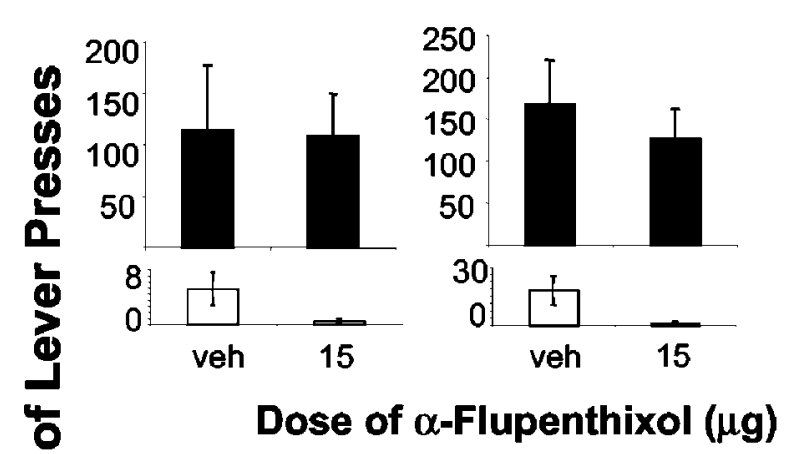

\section{है}

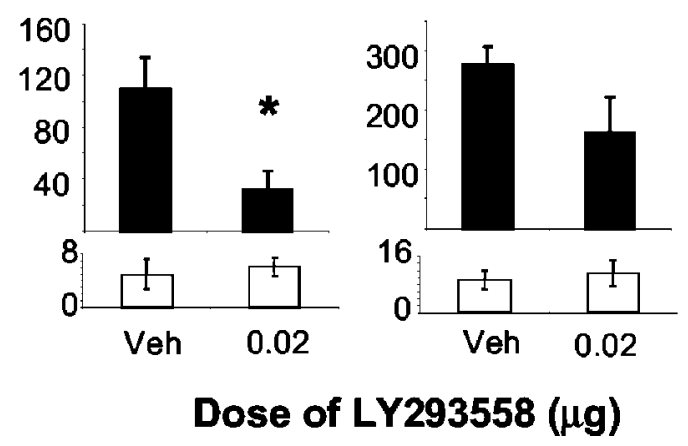

Figure 4. Effect of infusion of two doses of the $D_{1}-D_{2}$ dopamine receptor antagonist $\alpha$-flupenthixol (top panel; $n=5$ ) or the AMPA-KA antagonist LY293558 (bottom panel; $n=$ 6; also used in disconnection study) into the NAcc core on the mean \pm SEM number of responses on the active lever (dark bars) and inactive lever (open bars) for cocaine under a second-order schedule of cocaine reinforcement. Responses before self-administered cocaine during the first interval and after self-administered cocaine are given in the left and right panels. The asterisk denotes difference from vehicle (Veh) during that interval $(n=11)$.

reinforcement (Cardinal et al., 2002). Second-order schedules of reinforcement very effectively model this aspect of drug seeking, and behavioral analyses have revealed that responding for cocaine under a second-order schedule is mediated by at least three motivational processes. First, responding is controlled by drug reinforcement, because cocaine is available every $15 \mathrm{~min}$, and under this fixed interval schedule, typical scalloped patterns of responding for the drug are observed. Second, during these intervals, responding is maintained by contingent presentations of the cocaine-associated conditioned reinforcers, as evidenced by postreinforcement pauses (Kelleher and Goldberg, 1977) and the marked reduction of seeking responses when these CSs are not presented (Arroyo et al., 1998; Di Ciano and Everitt, 2003). Moreover, during the first period of drug seeking before cocaine is self-administered, responding is unaffected by the rate-altering and other pharmacological effects of cocaine. Third, selfadministered cocaine increases responses (Arroyo et al., 1998; Di Ciano and Everitt, 2003), which at least in part reflects a potentiation of the conditioned reinforcing properties of the cocaineassociated stimulus by this psychostimulant (Everitt and Robbins, 2000). Thus, changes in responding after blockade of DA or AMPA-KA receptors in either the BLA, NAcc core, or disconnection of these two structures could have reflected an influence on any of these processes, either separately or in combination.

\section{Cocaine seeking depends on amygdala-nucleus accumbens} core interactions

Accumulating evidence suggests that the integrated control over drug seeking depends on an amygdala-nucleus accumbens com- ponent of limbic cortical-ventral striatopallidal circuitry. Thus, lesions of the NAcc core or BLA reduced responding for cocaine under a second-order schedule (Whitelaw et al., 1996; Ito et al., 2004). In contrast, the potentiative effects of psychomotor stimulants on conditioned reinforcement depend on the integrity of the NAcc shell and central nucleus of the amygdala (Taylor and Robbins, 1986; Robledo et al., 1996; Parkinson et al., 1999; Ito et al., 2004). The data presented here extend our understanding of these neural mechanisms by providing evidence for a direct interaction between DA-dependent mechanisms in the BLA and glutamate receptors in the NAcc core in the control over cocaine seeking by associative mechanisms. Importantly, it was demonstrated that unilateral infusions of these drugs into either site alone were without effect, suggesting that serial interactions between the BLA and NAcc core underlie this behavior. This observation is underpinned by earlier, neurochemically nonspecific lesion studies showing the importance of functional interactions between the amygdala and NAcc in conditioned place preference (Everitt et al., 1991) and second-order conditioning (Setlow et al., 2002).

Dissociable neurochemical mechanisms in the BLA and NAcc core are critical for cue-controlled cocaine seeking

The present data clearly show that dissociable neurochemical mechanisms in the BLA and NAcc core contribute to cocaine seeking. Bilateral infusion of a mixed DA receptor antagonist into the NAcc core had no effect on responding for cocaine under a second-order schedule of reinforcement. These data are therefore consistent with the observation that DA efflux in the NAcc core, measured using in vivo microdialysis, also was not increased during cocaine seeking maintained by response-dependent presentations of CSs (Neisewander et al., 1996; Ito et al., 2000; Di Ciano et al., 2001a), whereas NAcc DA has been shown to be responsive to noncontingent (Pavlovian) presentation of CSs (Di Ciano et al., 1998; Ito et al., 2000; Weiss et al., 2000; Phillips et al., 2003).

In contrast, bilateral infusion of the AMPA-KA receptor antagonist LY293558 into the NAcc core did decrease drug seeking before self-administration of cocaine, consistent with our previous observations (Di Ciano and Everitt, 2001). In addition, glutamate efflux in the NAcc has been observed in animals engaged in active cocaine seeking (Kalivas and McFarland, 2003), whereas there was no change in DA levels during active cocaine seeking under the control of CSs (Neisewander et al., 1996; Di Ciano et al., 1998; Ito et al., 2000; Phillips et al., 2003). Similarly, inactivation of the NAcc core has been shown to decrease cue-induced reinstatement of drug seeking, whereas inactivation of the NAcc shell decreased locomotor activity (Fuchs et al., 2004), supporting our hypothesis that it is the NAcc core that is selectively involved in goal-directed behavior under the control of conditioned reinforcers (Parkinson et al., 1999; Di Ciano and Everitt, 2001). These converging data therefore indicate that drug seeking maintained by conditioned reinforcers is mediated by glutamate, especially AMPA-KA, receptors in the NAcc core and is distinct from Pavlovian influences over behavior that are dopamine dependent, as discussed above.

In contrast, the present data support a growing consensus that DA, but not glutamate, receptors within the BLA mediate the impact of conditioned reinforcers on cocaine seeking and other forms of goal-directed behavior (Hitchcott et al., 1997; Hitchcott and Phillips, 1998; See et al., 2001, 2003). Thus, we found that infusion of the AMPA-KA receptor antagonist LY293558 into the BLA had no effect on cocaine seeking. However, a slight increase in responding on the inactive lever was observed in the 
present experiment after infusion of LY293558 into the BLA, complementing our observation that inactivation of the BLA altered discriminative control over responding for cocaine under a second-order schedule of reinforcement (Di Ciano and Everitt, 2004). The results of the present experiments therefore extend our previous observation that a DA receptor antagonist decreased responding only when infused into the BLA and not into the NAcc core, suggesting that the effect of ventral tegmental area inactivation to reduce cocaine seeking under a second-order schedule was related to changes in DA efflux in its BLA terminal region and not the NAcc, as we had speculated (Di Ciano and Everitt, 2004).

In contrast to effects in the NAcc, infusion of the DA receptor antagonist $\alpha$-flupenthixol into the BLA dose dependently and greatly decreased cocaine seeking before the first infusion of cocaine when rats were drug free. However, this resultant low level of cocaine seeking was still increased after the self-administration of cocaine, indicating that although stimulus-controlled drug seeking depends on DA in the BLA, the cocaine-induced potentiation of this behavior persisted in the face of intra-BLA DA receptor antagonism, presumably reflecting the well established dependence of this effect on dopaminergic mechanisms in the NAcc (Taylor and Robbins, 1986; Wolterink et al., 1993; Parkinson et al., 1999). It is noteworthy that responding on the inactive lever was not affected by DA receptor blockade in the BLA. This confirms that the present manipulation did not produce any general impairment in motor activity and suggests that the effects on drug seeking were selective and reflected alterations in goaldirected behavior.

Infusion of DA or AMPA-KA receptor antagonists bilaterally into the NAcc core or BLA produced changes in cocaine seeking that were independent of any effects on responding on the inactive lever. This is consistent with previous studies that failed to find changes in lever pressing for food after intra-amygdala infusion of $\alpha$-flupenthixol (Beninger and Ranaldi, 1993) or on cueinduced reinstatement of extinguished cocaine seeking after infusion of selective $D_{1}$ and $D_{2}$ DA receptor antagonists into the amygdala (See et al., 2001). Although DA receptors in the NAcc core may contribute to simple motor activity, the present finding that responding did not decrease on the active lever suggests that DA in the NAcc is not involved in goal-directed responding for the CS. In contrast, infusion of the AMPA-KA receptor antagonist bilaterally into the NAcc core did decrease cocaine seeking, an effect that we have shown in a previous dose-response study to be related to decreased discriminative control over behavior by drug-associated conditioned reinforcers (Di Ciano and Everitt, 2001).

\section{Theoretical considerations}

Together, these findings are consistent with a conceptual framework that posits separate limbic cortical-striatal subsystems underlying dissociable components of goal-directed behavior. Thus, disconnection of the anterior cingulate cortex and NAcc revealed the importance of this subcircuitry for Pavlovian conditioned approach (Parkinson et al., 2000), whereas disconnection of the BLA and dorsal striatum revealed yet different subcircuitry underlying appetitive conditioned orienting (Han et al., 1997). These findings are significant in view of the contribution of separate prefrontal-NAcc and amygdala-NAcc systems to other aspects of goal-directed behavior. Thus, inactivation of the medial prefrontal cortex disrupted cocaine-induced (McFarland and Kalivas, 2001) and cue-induced (McLaughlin and See, 2003) reinstatement of extinguished drug seeking through interaction with glutamate-dependent mechanisms in the NAcc core (McFarland et al., 2003). However, lesions of this medial prefrontal cortex did not impair the acquisition of responding for cocaine (Weissenborn et al., 1997) or a natural reward (Pears et al., 2003) under second-order schedules of reinforcement, although they subtly changed the impact of omission of conditioned reinforcers on seeking responses. Indeed, the findings of the present study suggest that the medial prefrontal cortex may not contribute to drug seeking under a second-order schedule, because the disconnection effect would not have been seen if this region played an additional, parallel role in CS-controlled drug seeking as measured here through its projections to the NAcc. In addition to the NAcc and BLA, the dorsal striatum has also been shown to be important in cocaine seeking under a second-order schedule of reinforcement (Ito et al., 2002). This structure has been implicated in the learning of stimulus-response habits (White, 1996; Yin et al., 2004), which may be part of a complementary neural mechanism by which conditioned reinforcers control behavior. Future studies will help to define the ways in which these various influences on drug seeking depend on distinct limbiccorticostriatal loops and the interactions between them.

\section{References}

Arroyo M, Markou A, Robbins TW, Everitt BJ (1998) Acquisition, maintenance and reinstatement of intravenous cocaine self-administration under a second-order schedule of reinforcement in rats: effects of conditioned cues and continuous access to cocaine. Psychopharmacology (Berl) 140:331-344.

Beninger RJ, Ranaldi R (1993) Microinjections of flupenthixol into the caudate-putamen but not the nucleus accumbens, amygdala or frontal cortex of rats produce intra-session declines in food-rewarded operant responding. Behav Brain Res 55:203-212.

Caine SB, Lintz R, Koob GF (1992) Intravenous self-administration techniques in animals. In: Behavioral neuroscience: a practical approach (Sahgal A, ed), pp 117-143. Oxford: Oxford UP.

Cardinal RN (2000) Whisker, version 1.0, computer software. http://www. pobox.com/users/rudolf/whisker.

Cardinal RN, Parkinson JA, Hall J, Everitt BJ (2002) Emotion and motivation: the role of the amygdala, ventral striatum, and prefrontal cortex. Neurosci Biobehav Rev 26:321-352.

Christakou A, Robbins TW, Everitt BJ (2004) Prefrontal cortical-ventral striatal interactions involved in affective modulation of attentional performance: implications for corticostriatal circuit function. J Neurosci 24:773-780.

de Wit H, Stewart J (1981) Reinstatement of cocaine-reinforced responding in the rat. Psychopharmacology (Berl) 75:134-143.

Di Ciano P, Everitt BJ (2001) Dissociable effect of antagonism of NMDA and AMPA receptors in the nucleus accumbens core and shell on cocaineseeking behaviour. Neuropsychopharmacology 25:341-360.

Di Ciano P, Everitt BJ (2003) Differential control over drug-seeking behavior by drug-associated conditioned reinforcers, and discriminative stimuli predictive of drug availability. Behav Neurosci 117:952-960.

Di Ciano P, Everitt BJ (2004) Contribution of the ventral tegmental area to cocaine-seeking maintained by a drug-paired conditioned stimulus in rats. Eur J Neurosci 19:1-7.

Di Ciano P, Blaha CD, Phillips AG (1998) Conditioned changes in dopamine oxidation currents in the nucleus accumbens of rats by stimuli paired with self-administration or yoked administration of $d$-amphetamine. Eur J Neurosci 10:1121-1127.

Di Ciano P, Blaha CD, Phillips AG (2001a) Changes in dopamine efflux associated with extinction, Cs-induced and $d$-amphetamine-induced reinstatement of drug-seeking behaviour by rats. Behav Brain Res 120:147-158.

Di Ciano P, Cardinal RN, Cowell RA, Little SJ, Everitt BJ (2001b) Differential involvement of NMDA, AMPA/kainate, and dopamine receptors in the nucleus accumbens core in the acquisition and performance of Pavlovian approach behavior. J Neurosci 21:23-31.

Everitt BJ, Robbins TW (2000) Second-order schedules of drug reinforcement in rats and monkeys: measurement of reinforcing efficacy and drugseeking behaviour. Psychopharmacology (Berl) 153:17-30. 
Everitt BJ, Morris KA, O'Brien CP, Robbins TW (1991) The basolateral amygdala-ventral striatal system and conditioned place preference: further evidence of limbic-striatal interactions underlying reward-related processes. Neuroscience 42:1-18.

Fuchs RA, Evans KA, Parker MC, See RE (2004) Differential involvement of the core and shell subregions of the nucleus accumbens in conditioned cue-induced reinstatement of cocaine seeking in rats. Psychopharmacology (Berl), in press.

Goldberg SR, Kelleher RT, Morse WH (1975) Second-order schedules of drug injection. Fed Proc 34:1771-1776.

Groenewegen HJ, Wright CI, Beijer AVJ (1996) The nucleus accumbens: gateway for limbic structures to reach the motor system. In: Progress in brain research, Ed 1 (Holstege G, Bandler R, Saper CB, eds), pp 485-511. Oxford: Elsevier.

Han J-S, McMahan RW, Holland P, Gallagher M (1997) The role of an amygdalo-nigrostriatal pathway in associative learning. J Neurosci 17:3913-3919.

Hitchcott PK, Phillips GD (1998) Double dissociation of the behavioural effects of $\mathrm{R}(+)$ 7-OH-DPAT infusions in the central and basolateral amygdala nuclei upon Pavlovian and instrumental conditioned appetitive behaviours. Psychopharmacology (Berl) 140:458-469.

Hitchcott PK, Bonardi CM, Phillips GD (1997) Enhanced stimulus-reward learning by intra-amygdala administration of a D3 dopamine receptor agonist. Psychopharmacology (Berl) 133:240-248.

Ito R, Dalley JW, Howes SR, Robbins TW, Everitt BJ (2000) Dissociation in conditioned dopamine release in the nucleus accumbens core and shell in response to cocaine cues and during cocaine-seeking behavior in rats. J Neurosci 20:7489-7495.

Ito R, Dalley JW, Robbins TW, Everitt BJ (2002) Dopamine release in the dorsal striatum during cocaine-seeking behavior under the control of a drug-associated cue. J Neurosci 22:6247-6253.

Ito R, Robbins TW, Everitt BJ (2004) Differential control over drug seeking behavior by nucleus accumbens core and shell. Nat Neurosci 17:389-397.

Kalivas PW, McFarland K (2003) Brain circuitry and the reinstatement of cocaine-seeking behavior. Psychopharmacology (Berl) 22:44-56.

Kelleher RT (1966) Chaining and conditioned reinforcement. In: Operant behavior: areas of research and application (Honig WK, ed), pp 160-212. New York: Appleton-Century-Crofts.

Kelleher RT, Goldberg SR (1977) Fixed-interval responding under secondorder schedules of food presentation or cocaine injection. J Exp Anal Behav 28:221-231.

Keppel G (1991) Design and analysis. A researcher's handbook, Ed 3, pp 357-364. Englewood Cliffs, NJ: Prentice Hall.

McFarland K, Kalivas PW (2001) The circuitry mediating cocaine-induced reinstatement of drug-seeking behavior. J Neurosci 21:8655-8663.

McFarland K, Lapish CC, Kalivas PW (2003) Prefrontal glutamate release into the core of the nucleus accumbens mediates cocaine-induced reinstatement of drug-seeking behavior. J Neurosci 23:3531-3537.

McLaughlin J, See RE (2003) Selective inactivation of the dorsomedial prefrontal cortex and the basolateral amygdala attenuates conditioned-cued reinstatement of extinguished cocaine-seeking behavior in rats. Psychopharmacology (Berl) 168:57-65.

Neisewander JL, O'Dell LE, Tran-Nguyen LTL, Castaneda E, Fuchs RA (1996) Dopamine overflow in the nucleus accumbens during extinction and reinstatement of cocaine self-administration behavior. Neuropsychopharmacology 15:506-514.

Parkinson JA, Olmstead MC, Burns LH, Robbins TW, Everitt BJ (1999) Dissociation in effects of lesions of the nucleus accumbens core and shell on appetitive Pavlovian approach behavior and the potentiation of conditioned reinforcement and locomotor activity by D-amphetamine. J Neurosci 19:2401-2411.
Parkinson JA, Willoughby PJ, Robbins TW, Everitt BJ (2000) Disconnection of the anterior cingulate cortex and nucleus accumbens core impairs Pavlovian approach behavior: further evidence for limbic cortical-ventral striatopallidal systems. Behav Neurosci 114:42-63.

Paxinos G, Watson C (1996) The rat brain in stereotaxic coordinates, Ed 3. Sydney: Academic.

Pears A, Parkinson JA, Hopewell L, Everitt BJ, Roberts AC (2003) Lesions of the orbitofrontal but not medial prefrontal cortex disrupt conditioned reinforcement in primates. J Neurosci 23:11189-11201.

Phillips GD, Setzu E, Vugler A, Hitchcott PK (2003) Immunohistochemical assessment of mesotelencephalic dopamine activity during the acquisition and expression of Pavlovian versus instrumental behaviours. Neuroscience 117:755-767.

Robledo P, Robbins TW, Everitt BJ (1996) Effects of excitotoxic lesions of the central amygdaloid nucleus on the potentiation of reward-related stimuli by intra-accumbens amphetamine. Behav Neurosci 110:981-990.

Schindler CW, Panlilio LV, Goldberg SR (2002) Second-order schedules of drug self-administration in animals. Psychopharmacology (Berl) $163: 327-344$.

See RE (2002) Neural substrates of conditioned-cued relapse to drugseeking behavior. Pharmacol Biochem Behav 71:517-529.

See RE, Kruzich PJ, Grimm JW (2001) Dopamine, but not glutamate, receptor blockade in the basolateral amygdala attenuates conditioned reward in a rat model of relapse to cocaine-seeking behavior. Psychopharmacology (Berl) 154:301-310.

See RE, Fuchs RA, Ledford CC, McLaughlin J (2003) Drug addiction, relapse and the amygdala. Ann NY Acad Sci 985:294-307.

Setlow B, Holland PC, Gallagher M (2002) Disconnection of the basolateral amygdala complex and nucleus accumbens impairs appetitive pavlovian second-order conditioned responses. Behav Neurosci 116:267-275.

Shaham Y, Shalev U, Lu L, De Wit H, Stewart J (2002) The reinstatement model of drug relapse: history, methodology and major findings. Psychopharmacology (Berl) 168:3-20.

Taylor JR, Robbins TW (1986) 6-Hydroxydopamine lesions of the nucleus accumbens, but not of the caudate nucleus, attenuate enhanced responding with reward-related stimuli produced by intra-accumbens $d$-amphetamine. Psychopharmacology (Berl) 90:390-397.

Weiss F, Maldonado-Vlaar CS, Parsons LH, Kerr TM, Smith DL, Ben-Shahar O (2000) Control of cocaine-seeking behavior by drug-associated stimuli in rats: effects on recovery of extinguished operant-responding and extracellular dopamine levels in amygdala and nucleus accumbens. Proc Natl Acad Sci USA 97:4321-4326.

Weissenborn R, Robbins TW, Everitt BJ (1997) Effects of medial prefrontal or anterior cingulate cortex lesions on responding for cocaine under fixed-ratio and second-order schedules of reinforcement. Psychopharmacology (Berl) 134:242-257.

White NM (1996) Addictive drugs as reinforcers: multiple partial actions on memory systems. Addiction 91:921-949.

Whitelaw RB, Markou A, Robbins TW, Everitt BJ (1996) Excitotoxic lesions of the basolateral amygdala impair the acquisition of cocaine-seeking behaviour under a second-order schedule of reinforcement. Psychopharmacology (Berl) 127:213-224.

Wolterink G, Phillips G, Cador M, Donselaar-Wolterink I, Robbins TW, Everitt BJ (1993) Relative roles of ventral striatal $D_{1}$ and $D_{2}$ dopamine receptors in responding with conditioned reinforcement. Psychopharmacology (Berl) 110:355-364.

Yin HH, Knowlton BJ, Balleine BW (2004) Lesions of dorsolateral striatum preserve outcome expectancy but disrupt habit formation in instrumental learning. Eur J Neurosci 19:181-189. 